\title{
Non-desired transitions and sliding-mode control of a multi-DOF mechanical system with stick-slip oscillations
}

\author{
Eva M. Navarro-López ${ }^{\mathrm{a}, *}$, Eduardo Licéaga-Castro ${ }^{\mathrm{b}}$ \\ a School of Computer Science, CICADA, The University of Manchester, Oxford Road, Kilburn Building, Manchester M13 9PL, United Kingdom \\ ${ }^{\mathrm{b}}$ Universidad Carlos III de Madrid, Depto. de Ingeniería de Sistemas y Automática Leganés, 28911 Madrid, Spain
}

\section{A R T I C L E I N F O}

\section{Article history:}

Accepted 5 August 2008

Communicated by Prof. Ji-Huan He

\begin{abstract}
A B S T R A C T
Systems with discontinuous elements exhibit a wide variety of complex phenomena which must be considered in the control design process. A dynamical sliding-mode control is used to avoid different bit sticking problems appearing in conventional vertical oilwell drillstrings. The aim of the control system is to drive the rotary velocities of drillstring components to specified values. A discontinuous lumped-parameter torsional model of four degrees of freedom is considered. This model is more generic than those so far reported in the literature. The closed-loop system dynamics have four discontinuity surfaces. One of these surfaces is introduced in order to accomplish the control goal despite variations of key drilling parameters, such as, the weight on the bit, the top-rotary velocity and friction characteristics. Self-excited bit stick-slip oscillations and sticking phenomena are avoided with the controller here proposed. Moreover, an alternative procedure to investigate the stick-slip motion is presented, it is based on the study of the stability characteristics of the different system equilibria and their relationships to different sliding motions. (c) 2008 Elsevier Ltd. All rights reserved.
\end{abstract}

\section{Introduction}

Bifurcation analysis of mechanical systems with friction-induced stick-slip oscillations has attracted the attention of researchers in the last two decades [1-8]. Other non-desired phenomena in mechanical oscillators with friction and other nonsmooth events have been also studied [9-16]. All these works usually deal with two-degrees-of-freedom (DOF) systems. Exceptionally, 3-DOF systems including discontinuous elements are analysed [8,13,16-18]. Stick-slip periodic motion is studied from different viewpoints in these systems. Alternatively, this paper uses a new method in order to characterise the stick-slip phenomenon in a discontinuous mechanical system subject to friction and with more than 2-DOF, as well as multiple switching surfaces. The method is based on the properties of the existing sliding motions and the relationships between the different types of system equilibria, the properties of the switching surfaces and the boundaries of the sliding regions.

A 4-DOF lumped-parameter discontinuous model is considered which corresponds to the torsional model of a simplified conventional vertical oilwell drillstring. This model is a particular case of the generic $n$-dimensional model proposed in [19], and considers the drill pipe and drill collars dynamics. It is more general than the torsional lumped-parameter models of one and two DOF previously proposed [20-28]. Most of these works are focused on the study of bit stick-slip oscillations. Some works otherwise study whirl and chaotic behaviours associated with lateral motion in addition to their relationships with stick-slip phenomenon [20,29,30]. However, these studies are given for 2-DOF drillstring models. The 3-DOF drilling system studied in [18] is different than the drillstring analysed in this paper.

\footnotetext{
* Corresponding author. Tel.: +44(0) 1613066000.

E-mail addresses: eva.navarrolopez@gmail.com (E.M. Navarro-López), eduardo.liceagacastro@uc3m.es (E. Licéaga-Castro).
} 
Following the ideas given in [19], an alternative procedure for analysing bit stick-slip phenomenon and transitions between several bit dynamics is given in this paper. The physical phenomenon can be described mathematically as a sliding motion, which occurs when the bit velocity is zero. The existence of this sliding motion depends on the weight on the bit (WOB) and the torque applied by the surface motor. Such a regime is the main cause of bit sticking problems. By introducing another discontinuity surface and forcing the system to evolve along this new surface, a dynamical sliding-mode control is proposed. On the new surface, the bit speed will follow the top-rotary-system speed after reasonable time, without bit sticking phenomena. Sliding-mode control aiming at eliminating friction-induced stick-slip oscillations is not usually used. Some previous sliding-mode-based results are given for other control goals [31], however, no bifurcation analysis is done.

The relationships between the existing sliding motions and the characteristics of different types of system equilibria, are established for the open and closed-loop configurations. A crucial feature of the closed-loop system is the existence of multiple switching surfaces. The analysis of such a system is possible by studying the properties of the unique quasiequilibrium of the closed-loop system. Moreover, a multiparameter-kind bifurcation analysis is carried out. That is, changes in drillstring behaviour are studied through the variations in three key parameters: (1) the WOB, (2) the rotary speed, and (3) the torque given by the surface motor. This is also a new contribution, which is only reported in [19], due to the fact that drillstrings bifurcation analysis does not normally combine these three parameters. In most of the previous works, the WOB is not taken into account. In [20], the influence of the WOB is considered, however, the drillstring model has 2-DOF. Finally, it is pointed out that in [19], no control solution for the stick-slip problem is proposed.

The range of parameters which lead to a free bit-stick-slip oscillatory system is also identified. This analysis is a novel approach to understand and design control systems for drillstrings models with more than 2-DOF.

The main features of the closed-loop system presented in this paper are

- The existence of multiple switching surfaces.

- The control goal is achieved by eliminating the open-loop standard equilibrium.

- There exists a unique quasiequilibrium point on one of the switching surfaces. This equilibrium has the velocities equal to the reference value and is asymptotically stable for typical operating conditions.

- The controlled system response improves in many aspects the response obtained with typical PI-type controllers, specially, concerning the robustness under WOB, velocity and controller parameters changes. It is an alternative control solution to those previously reported (vibration absorber-type [22,23], PI-type control [20,25,32,33], linear quadratic regulator [28] and linear $H_{\infty}$ control [27]).

The model and control were proposed in [34], however, in this paper, the analysis is extended and corrected.

\section{Torsional model of a drillstring}

Three main parts can be highlighted in a conventional vertical oilwell drillstring: (1) the surface rotating mechanism, (2) a set of drill pipes screwed one to each other, (3) the bottom-hole assembly (BHA) consisting of the drill collars, the stabilizers, a heavy-weight drill pipe and the bit (the cutting device). In this paper, the BHA, excepting the bit, will be considered as one block referred to as drill collars.

Fig. 1 depicts a simplified drillstring torsional model. It consists of four elements: (1) the top-rotary system $\left(J_{\mathrm{r}}\right),(2)$ the drill pipes $\left(J_{\mathrm{p}}\right),(3)$ the drill collars $\left(J_{1}\right)$, and $(4)$ the bit $\left(J_{\mathrm{b}}\right)$. The inertias are connected one to each other by linear springs with torsional stiffness $\left(k_{\mathrm{t}}, k_{\mathrm{tl}}, k_{\mathrm{tb}}\right)$ and torsional damping $\left(c_{\mathrm{t}}, c_{\mathrm{tl}}, c_{\mathrm{tb}}\right)$. A viscous damping torque is considered at the top-drive system $\left(T_{a_{\mathrm{r}}}\right)$ and at the bit $\left(T_{a_{\mathrm{b}}}\right)$. A friction torque $\left(T_{\mathrm{f}_{\mathrm{b}}}\right)$ is considered acting at the bit. The equations of motion are

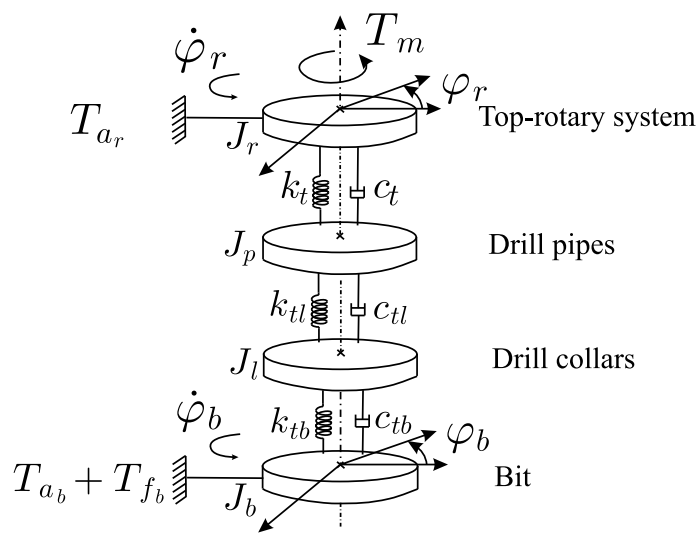

Fig. 1. Mechanical model describing the torsional behaviour of a simplified drillstring. 


$$
\begin{aligned}
& \ddot{\varphi}_{\mathrm{r}}=-\frac{c_{\mathrm{t}}}{J_{\mathrm{r}}}\left(\dot{\varphi}_{\mathrm{r}}-\dot{\varphi}_{\mathrm{p}}\right)-\frac{k_{\mathrm{t}}}{J_{\mathrm{r}}}\left(\varphi_{\mathrm{r}}-\varphi_{\mathrm{p}}\right)+\frac{T_{\mathrm{m}}-T_{a_{\mathrm{r}}}\left(\dot{\varphi}_{\mathrm{r}}\right)}{J_{\mathrm{r}}}, \\
& \ddot{\varphi}_{\mathrm{p}}=\frac{c_{\mathrm{t}}}{J_{\mathrm{p}}}\left(\dot{\varphi}_{\mathrm{r}}-\dot{\varphi}_{\mathrm{p}}\right)+\frac{k_{\mathrm{t}}}{J_{\mathrm{p}}}\left(\varphi_{\mathrm{r}}-\varphi_{\mathrm{p}}\right)-\frac{c_{\mathrm{tl}}}{J_{\mathrm{p}}}\left(\dot{\varphi}_{\mathrm{p}}-\dot{\varphi}_{\mathrm{l}}\right)-\frac{k_{\mathrm{tl}}}{J_{\mathrm{p}}}\left(\varphi_{\mathrm{p}}-\varphi_{\mathrm{l}}\right), \\
& \ddot{\varphi}_{\mathrm{l}}=\frac{c_{\mathrm{tl}}}{J_{\mathrm{l}}}\left(\dot{\varphi}_{\mathrm{p}}-\dot{\varphi}_{\mathrm{l}}\right)+\frac{k_{\mathrm{tl}}}{J_{\mathrm{l}}}\left(\varphi_{\mathrm{p}}-\varphi_{\mathrm{l}}\right)-\frac{c_{\mathrm{tb}}}{J_{\mathrm{l}}}\left(\dot{\varphi}_{\mathrm{l}}-\dot{\varphi}_{\mathrm{b}}\right)-\frac{k_{\mathrm{tb}}}{J_{\mathrm{l}}}\left(\varphi_{\mathrm{l}}-\varphi_{\mathrm{b}}\right), \\
& \ddot{\varphi}_{\mathrm{b}}=\frac{c_{\mathrm{tb}}}{J_{\mathrm{b}}}\left(\dot{\varphi}_{\mathrm{l}}-\dot{\varphi}_{\mathrm{b}}\right)+\frac{k_{\mathrm{tb}}}{J_{\mathrm{b}}}\left(\varphi_{\mathrm{l}}-\varphi_{\mathrm{b}}\right)-\frac{T_{\mathrm{b}}\left(\dot{\varphi}_{\mathrm{b}}\right)}{J_{\mathrm{b}}},
\end{aligned}
$$

with $\varphi_{i}, \dot{\varphi}_{i}(i \in\{r, p, l, b\})$ the angular displacements and angular velocities of the drillstring elements, respectively. $T_{\mathrm{m}}$ is the torque applied by the electrical motor at the surface. The actuator dynamics is not considered, and $T_{\mathrm{m}}=u$, with $u$ the control input. $T_{a_{\mathrm{r}}}=c_{\mathrm{r}} \dot{\varphi}_{\mathrm{r}}$, with $c_{\mathrm{r}}$ the viscous damping coefficient. The system state vector $\mathbf{x}$ is defined as

$$
\mathbf{x}=\left(\dot{\varphi}_{\mathrm{r}}, \varphi_{\mathrm{r}}-\varphi_{\mathrm{p}}, \dot{\varphi}_{\mathrm{p}}, \varphi_{\mathrm{p}}-\varphi_{1}, \dot{\varphi}_{\mathrm{l}}, \varphi_{\mathrm{l}}-\varphi_{\mathrm{b}}, \dot{\varphi}_{\mathrm{b}}\right)^{\mathrm{T}}=\left(x_{1}, x_{2}, x_{3}, x_{4}, x_{5}, x_{6}, x_{7}\right)^{\mathrm{T}}
$$

Finally, $T_{\mathrm{b}}\left(x_{7}\right)=T_{a_{\mathrm{b}}}\left(x_{7}\right)+T_{\mathrm{f}_{\mathrm{b}}}\left(x_{7}\right)$ is the torque on the bit, where $T_{a_{\mathrm{b}}}\left(x_{7}\right)=c_{\mathrm{b}} x_{7}$ represents the influence of the mud drilling on the bit behaviour and $T_{\mathrm{f}_{\mathrm{b}}}$ is the friction modelling the bit-rock contact defined as

$$
T_{\mathrm{f}_{\mathrm{b}}}\left(x_{7}\right)=W_{\mathrm{ob}} R_{\mathrm{b}} \mu_{\mathrm{b}}\left(x_{7}\right) \operatorname{sgn}\left(x_{7}\right),
$$

$W_{\mathrm{ob}}>0$ is the weight on the bit, $R_{\mathrm{b}}>0$ is the bit radius and $\mu_{\mathrm{b}}\left(x_{7}\right)$ is the bit dry friction coefficient considered as

$$
\mu_{\mathrm{b}}\left(x_{7}\right)=\mu_{c_{\mathrm{b}}}+\left(\mu_{\mathrm{s}_{\mathrm{b}}}-\mu_{c_{\mathrm{b}}}\right) \mathrm{e}^{-\frac{\gamma_{\mathrm{b}}}{v_{\mathrm{f}}}\left|x_{7}\right|}
$$

where $\mu_{\mathrm{s}_{\mathrm{b}}}, \mu_{\mathrm{c}_{\mathrm{b}}} \in(0,1)$ are the static and Coulomb friction coefficients associated with $J_{\mathrm{b}} ; 0<\gamma_{\mathrm{b}}<1$ and $v_{\mathrm{f}}>0$. The exponential decaying behaviour of $T_{\mathrm{b}}$ coincides with experimental bit torque values [20,21,32].

Using (2), system (1d) can be written as

$$
\begin{aligned}
& \dot{x}_{1}=\frac{1}{J_{\mathrm{r}}}\left[-\left(c_{\mathrm{t}}+c_{\mathrm{r}}\right) x_{1}-k_{\mathrm{t}} x_{2}+c_{\mathrm{t}} x_{3}+u\right], \quad \dot{x}_{2}=x_{1}-x_{3}, \\
& \dot{x}_{3}=\frac{1}{J_{\mathrm{p}}}\left[c_{\mathrm{t}} x_{1}+k_{\mathrm{t}} x_{2}-\left(c_{\mathrm{t}}+c_{\mathrm{tl}}\right) x_{3}-k_{\mathrm{t} 1} x_{4}+c_{\mathrm{t} 1} x_{5}\right], \quad \dot{x}_{4}=x_{3}-x_{5}, \\
& \dot{x}_{5}=\frac{1}{J_{1}}\left[c_{\mathrm{t} \mathrm{l}} x_{3}+k_{\mathrm{t} \mathrm{l}} x_{4}-\left(c_{\mathrm{tl}}+c_{\mathrm{tb}}\right) x_{5}-k_{\mathrm{tb}} x_{6}+c_{\mathrm{tb}} x_{7}\right], \quad \dot{x}_{6}=x_{5}-x_{7}, \\
& \dot{x}_{7}=\frac{1}{J_{\mathrm{b}}}\left[c_{\mathrm{tb}} x_{5}+k_{\mathrm{tb}} x_{6}-\left(c_{\mathrm{tb}}+c_{\mathrm{b}}\right) x_{7}-T_{\mathrm{f}_{\mathrm{b}}}\left(x_{7}\right)\right],
\end{aligned}
$$

or in a compact form $\dot{\mathbf{x}}(t)=\mathbf{A} \mathbf{x}(t)+\mathbf{B} u+\mathbf{T}_{\mathbf{f}}(\mathbf{x}(t))$.

In the following simulations, the data corresponding to a real drillstring design reported in [35] are used. The drill pipeline consists of 130 drill pipes of 5 inches of outer diameter (OD), 4.408 inches of inner diameter (ID) and 9 metres of length, and a roller-cone bit of $6^{\frac{1}{2}}$ (ID), $12^{\frac{1}{4}}$ (OD) and 1.5 metres of length. Then,

$$
\begin{aligned}
& J_{\mathrm{r}}=930 \mathrm{~kg} \mathrm{~m}^{2}, \quad J_{\mathrm{b}}=471.9698 \mathrm{~kg} \mathrm{~m}^{2}, \quad R_{\mathrm{b}}=0.155575 \mathrm{~m}, \\
& J_{\mathrm{p}}=2782.25 \mathrm{~kg} \mathrm{~m}^{2}, \quad J_{\mathrm{l}}=750 \mathrm{~kg} \mathrm{~m}^{2}, \quad c_{\mathrm{r}}=425 \mathrm{~N} \mathrm{~m} \mathrm{~s} / \mathrm{rad}, \\
& k_{\mathrm{t}}=698.063 \mathrm{~N} \mathrm{~m} / \mathrm{rad}, \quad k_{\mathrm{tl}}=1080 \mathrm{~N} \mathrm{~m} / \mathrm{rad}, \quad \mu_{\mathrm{c}_{\mathrm{b}}}=0.5, \quad \mu_{\mathrm{s}_{\mathrm{b}}}=0.8, \\
& k_{\mathrm{tb}}=907.48 \mathrm{~N} \mathrm{~m} / \mathrm{rad}, \quad c_{\mathrm{t}}=139.6126 \mathrm{~N} \mathrm{~m} \mathrm{~s} / \mathrm{rad}, \quad \gamma_{\mathrm{b}}=0.9, \quad v_{\mathrm{f}}=1, \\
& c_{\mathrm{tl}}=190 \mathrm{~N} \mathrm{~m} \mathrm{~s} / \mathrm{rad}, \quad c_{\mathrm{tb}}=181.49 \mathrm{~N} \mathrm{~m} \mathrm{~s} / \mathrm{rad}, \quad c_{\mathrm{b}}=50 \mathrm{~N} \mathrm{~m} \mathrm{~s} / \mathrm{rad} .
\end{aligned}
$$

\section{Key dynamical properties and transitions in the open-loop system}

The two dynamical properties that determine the existence of self-excited bit stick-slip oscillations and permanent stuck bit are: (1) the existence of a sliding motion which originates an asymptotically stable quasiequilibrium on the sliding surface, and (2) the existence of a standard equilibrium which can become unstable. In the case of an $n$-DOF model, these phenomena depend on three key drilling parameters [19]: (1) the WOB, (2) the steady rotary speed, (3) the torque applied by the surface motor $(u)$. In this paper, these results are adapted and expanded to a 4-DOF model.

The bit stick phenomenon occurs when $\dot{x}_{7}=x_{7}=0$ in the last equation of (5). Under this condition, due to Eqs. (3), (4), a sliding regime may appear. This regime can be stated by the discontinuity or switching surface, $\Sigma_{\mathrm{b}}$, and the sliding region $\widetilde{\Sigma}_{\mathrm{b}} \subset \Sigma_{\mathrm{b}}$, with:

$$
\begin{aligned}
& \sigma_{\mathrm{b}}(\mathbf{x})=x_{7}, \quad \Sigma_{\mathrm{b}}:=\left\{\mathbf{x} \in \mathbb{R}^{7}: \sigma_{\mathrm{b}}(\mathbf{x})=0\right\}, \\
& \widetilde{\Sigma}_{\mathrm{b}}=\left\{\mathbf{x} \in \Sigma_{\mathrm{b}}:\left|k_{\mathrm{tb}} x_{6}+c_{\mathrm{tb}} x_{5}\right|<W_{\mathrm{ob}} R_{\mathrm{b}} \mu_{\mathrm{s}_{\mathrm{b}}}\right\} .
\end{aligned}
$$


Proposition 1. Consider system (5). Let the set:

$$
\mathscr{S}_{\mathrm{b}}:=\left\{\mathbf{x} \in \mathbb{R}^{7}:\left|c_{\mathrm{t}_{\mathrm{b}}} x_{5}+k_{\mathrm{tb}} x_{6}\right|<\left(c_{\mathrm{tb}}+c_{\mathrm{b}}\right)\left|x_{7}\right|+W_{\mathrm{ob}} R_{\mathrm{b}} \mu_{\mathrm{b}}\left(x_{7}\right)\right\},
$$

with $\mu_{\mathrm{b}}\left(x_{7}\right)$ as defined in (4). If $\mathbf{x} \in \mathscr{S}_{\mathrm{b}}$ then the system trajectory enters a sliding motion in $\widetilde{\Sigma}_{\mathrm{b}} \subset \Sigma_{\mathrm{b}}$.

Proof. It follows from restricting the results given in [19] to system (5).

Proposition 1 does not assert that once the system trajectory enters the sliding regime in $\Sigma_{\mathrm{b}}$, it will remain in it thereafter. That is, the trajectory may leave the sliding mode. However, if this happens, the trajectory eventually returns once again into the sliding regime. Once the trajectory is in a sliding regime, $\widetilde{\Sigma}_{\mathrm{b}}$ can change from being attractive (stable) to be repulsive (unstable), and due to this fact the system trajectory can leave the sliding motion. $\widetilde{\Sigma}_{\mathrm{b}}$ is attractive for $\mathbf{x} \in \mathscr{S}_{\mathrm{b}}$ [36,37].

The system dynamics while evolving in $\Sigma_{\mathrm{b}}$ have the form $\dot{x}=f_{s b}(\mathbf{x}, u)$, where $f_{s b}$ is the equivalent dynamics in $\Sigma_{\mathrm{b}}$ [31,37]. The quasiequilibrium on the switching surface, $\tilde{\mathbf{x}}_{\mathrm{b}} \in \Sigma_{\mathrm{b}}$, such that $f_{s b}\left(\tilde{\mathbf{x}}_{\mathrm{b}}, u\right)=0$ is

$$
\tilde{x}_{\mathrm{b}, 1}=\tilde{x}_{\mathrm{b}, 3}=\tilde{x}_{\mathrm{b}, 5}=0, \quad \tilde{x}_{\mathrm{b}, 2}=\frac{u}{k_{\mathrm{t}}}, \quad \tilde{x}_{\mathrm{b}, 4}=\frac{u}{k_{\mathrm{tl}}}, \quad \tilde{x}_{\mathrm{b}, 6}=\frac{u}{k_{\mathrm{tb}}} .
$$

The standard equilibrium for $x_{7}>0, \overline{\mathbf{x}} \in \mathbb{R}^{7}$, such that $\mathbf{A} \overline{\mathbf{x}}+\mathbf{B} u+\left.\mathbf{T}_{\mathrm{f}}(\overline{\mathbf{x}})\right|_{T_{\mathrm{f}_{\mathrm{b}}}=T_{\mathrm{f}_{\mathrm{b}}^{+}}}=0$, with

$$
T_{\mathrm{f}_{\mathrm{b}}}^{+}\left(x_{7}\right)=W_{\mathrm{ob}} R_{\mathrm{b}}\left[\mu_{\mathrm{c}_{\mathrm{b}}}+\left(\mu_{\mathrm{s}_{\mathrm{b}}}-\mu_{\mathrm{c}_{\mathrm{b}}}\right) \exp ^{-\frac{\gamma_{\mathrm{b}}}{v_{\mathrm{f}}} x_{7}}\right]
$$

is

$$
\begin{aligned}
& \bar{x}_{1}=\bar{x}_{3}=\bar{x}_{5}=\bar{x}_{7}>0, \quad u-\left(c_{\mathrm{r}}+c_{\mathrm{b}}\right) \bar{x}_{7}-T_{\mathrm{f}_{\mathrm{b}}}^{+}\left(\bar{x}_{7}, W_{\mathrm{ob}}\right)=0, \\
& \bar{x}_{2}=\frac{h\left(\bar{x}_{7}, u, W_{\mathrm{ob}}\right)}{k_{\mathrm{t}}}, \quad \bar{x}_{4}=\frac{h\left(\bar{x}_{7}, u, W_{\mathrm{ob}}\right)}{k_{\mathrm{tl}}}, \quad \bar{x}_{6}=\frac{h\left(\bar{x}_{7}, u, W_{\mathrm{ob}}\right)}{k_{\mathrm{tb}}},
\end{aligned}
$$

where $h\left(\bar{x}_{7}, u, W_{\mathrm{ob}}\right)=\left[c_{\mathrm{r}} T_{\mathrm{f}_{\mathrm{b}}}^{+}\left(\bar{x}_{7}, W_{\mathrm{ob}}\right)+c_{\mathrm{b}} u\right] /\left(c_{\mathrm{r}}+c_{\mathrm{b}}\right)$, and $u>W_{\mathrm{ob}} R_{\mathrm{b}} \mu_{\mathrm{s}_{\mathrm{b}}}>0$.

The quasiequilibrium $\tilde{\mathbf{x}}_{\mathrm{b}}$ is asymptotically stable [19]. This implies that if $\tilde{\mathbf{x}}_{\mathrm{b}} \in \widetilde{\Sigma}_{\mathrm{b}}$, the bit will be permanently stuck. On the other hand, the bit will move with a constant positive velocity (convergence to $\overline{\mathbf{x}}$ ) when $\tilde{\mathbf{x}}_{\mathrm{b}} \notin \widetilde{\Sigma}_{\mathrm{b}}$ and is far away from the boundary of $\widetilde{\Sigma}_{\mathrm{b}}$, such a condition is accomplished when $u$ is sufficiently larger than $W_{\mathrm{ob}} R_{\mathrm{b}} \mu_{\mathrm{s}}$.

The standard equilibrium $\overline{\mathbf{x}}$ is locally asymptotically stable depending on $W_{\mathrm{ob}}, u$ and $\bar{x}_{7}$. The loss of stability of $\overline{\mathbf{x}}$ is due to the presence of Hopf bifurcations (HB). In particular, multiple subcritical Hopf bifurcations give rise to branches of unstable periodic orbits. The bifurcation diagram of $\left(W_{\mathrm{ob}}, \bar{x}_{7}\right)$ for a fixed $u$ is shown in Fig. 2 (1). For each value of $u$, a different bifurcation diagram is obtained. The bifurcation diagram of $\left(u, \bar{x}_{7}\right)$ and a fixed $W_{\text {ob }}$ is depicted in Fig. 2 (2). The stable branches represent the values of $\left(W_{\mathrm{ob}}, \bar{x}_{7}\right)$ and $\left(u, \bar{x}_{7}\right)$ for which $\overline{\mathbf{x}}$ is stable. The unstable branches represent the values of the parameters for which $\overline{\mathbf{x}}$ is unstable. The equilibrium $\overline{\mathbf{x}}$ is stable when: (1) for a fixed $u$, the $W_{\mathrm{ob}}$ is small enough, (2) for a fixed $W_{\mathrm{ob}}$, the torque $u$ is large enough.

The characteristics of $\widetilde{\Sigma}_{\mathrm{b}}, \tilde{\mathbf{x}}_{\mathrm{b}}, \mathscr{S}_{\mathrm{b}}$ and $\overline{\mathbf{x}}$ and the relationships among them define three dynamical regimes: (1) stick-slip at $x_{7}$, that is, the trajectory enters and leaves repeatedly the sliding mode; (2) permanent stuck bit, i.e., $\mathbf{x}(t) \in \widetilde{\Sigma}_{\mathrm{b}}, \forall t>t_{s b} ;$ and (3) after a certain time, the bit moves with a positive constant velocity, $\mathbf{x}(t)$ converges to $\overline{\mathbf{x}}$. The stick-slip situation is depicted in Fig. 3, for $W_{\mathrm{ob}}=97347 \mathrm{~N}, u=10 \mathrm{k} \mathrm{N} \mathrm{m}$. In the simulation, $\overline{\mathbf{x}}$ is obtained using Newton-Raphson's method.

(1)

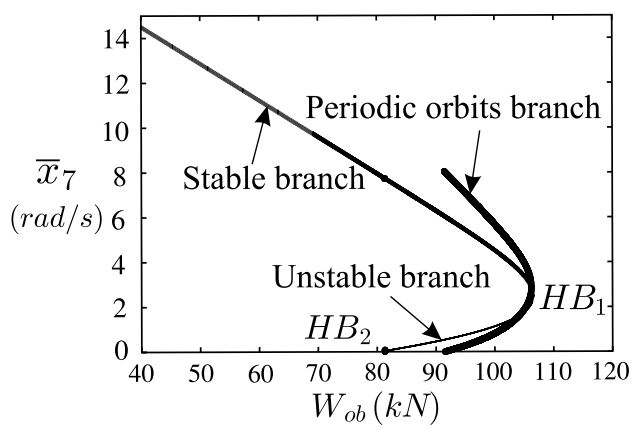

(2)

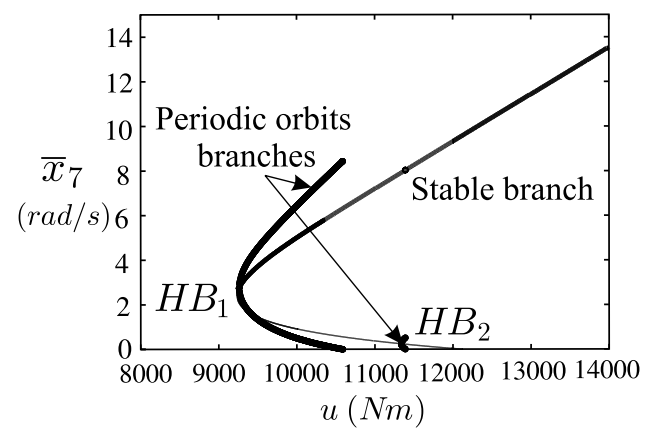

Fig. 2. Bifurcation diagrams for system (5): (1) $\left(W_{\mathrm{ob}}, \bar{x}_{7}\right)$ for a fixed $u=10 \mathrm{kNm},(2)\left(u, \bar{x}_{7}\right)$ for a fixed $W_{\mathrm{ob}}=97347 \mathrm{~N}$. The bifurcation diagrams have been obtained with XPPAUT [38]. 
(1)

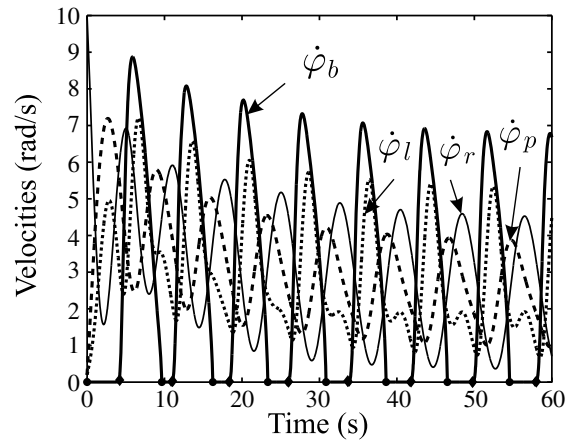

(2)

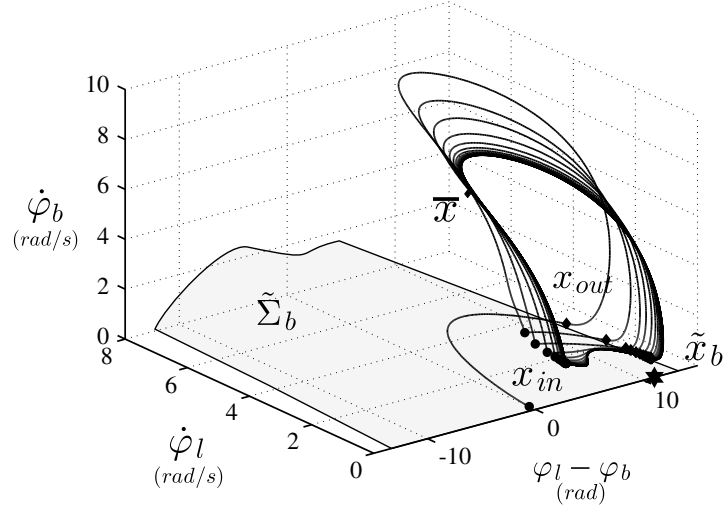

Fig. 3. Stick-slip in system (5): (1) angular velocities, (2) trajectory of the system in the space $\left(\varphi_{1}-\varphi_{\mathrm{b}}, \dot{\varphi}_{1}, \dot{\varphi}_{\mathrm{b}}\right)$. $\mathbf{x}_{\mathrm{in}}(\boldsymbol{\bullet})$ and $\mathbf{x}_{\mathrm{out}}(\bullet)$ are the points at which the system trajectory enters and goes out of the sticking region. $\star$ quasiequilibrium point $\left(\tilde{\mathbf{x}}_{\mathrm{b}}\right), \widetilde{\Sigma}_{\mathrm{b}}$ sliding region when $\dot{\varphi}_{\mathrm{b}}=0$.

\section{Sliding-mode-based controller}

The control design specifications are to eliminate the bit sticking phenomena, to drive the bit velocity to a desired value, and to reduce the influence of parameters changes. Robustness specifications consider $W_{\text {ob }}$ and bit-rock contact variations. The control strategy consists in introducing a switching surface and forcing the system state into a sliding regime on this surface. The function defining the induced sliding regime is

$$
\begin{aligned}
& \sigma_{\mathrm{r}}(\mathbf{x}, t)=\left(x_{1}-\Omega\right)+\lambda_{\mathrm{r}} \int_{0}^{t}\left[x_{1}(\tau)-\Omega\right] \mathrm{d} \tau+\lambda_{\mathrm{r}} \int_{0}^{t}\left[x_{1}(\tau)-x_{7}(\tau)\right] \mathrm{d} \tau=\left(x_{1}-\Omega\right)+\lambda_{\mathrm{r}}\left(x_{8}+x_{9}\right), \\
& \dot{x}_{8}=x_{1}-\Omega, \quad \dot{x}_{9}=x_{1}-x_{7},
\end{aligned}
$$

where $\Omega>0$ is the desired velocity value and $\lambda_{\mathrm{r}}>0$. If $\sigma_{\mathrm{r}}$ is zero, $x_{7}$ will approach $x_{1}$ and $x_{1}$ will approach $\Omega$. For $\sigma_{\mathrm{r}}$ to approach zero, it is imposed that:

$$
\dot{\sigma}_{\mathrm{r}}=-\eta \operatorname{sgn}\left(\sigma_{\mathrm{r}}\right)
$$

with $\eta$ a constant chosen in order to have a sliding motion on $\sigma_{\mathrm{r}}=0$. From (12) and (13), the following control is obtained

$$
u=c_{\mathrm{t}}\left(x_{1}-x_{3}\right)+k_{\mathrm{t}} x_{2}+c_{\mathrm{r}} x_{1}-J_{\mathrm{r}}\left[\lambda_{\mathrm{r}}\left(x_{1}-\Omega\right)+\lambda_{\mathrm{r}}\left(x_{1}-x_{7}\right)+\eta \operatorname{sign}\left(\sigma_{\mathrm{r}}\right)\right] .
$$

\subsection{Closed-loop sliding motions: multiple switching surfaces}

There exist two discontinuous elements in the controlled system: control (14) and the friction at the bit. The relationships between the two sliding regimes associated with each of these elements will be studied in this section.

Proposition 2. Consider system (5) with control (14) and (12). If $\eta>0$ then any trajectory of the system enters a sliding motion on $\sigma_{\mathrm{r}}(\mathbf{x}, t)=0$.

Proof. The proof is divided into two parts. First, it is shown that there exists a sliding mode. Second, the trajectories are shown to reach the sliding surface in finite time.

Since $u$ was proposed in such a way that (13) is accomplished, it follows that $\sigma_{\mathrm{r}} \dot{\sigma}_{\mathrm{r}}<0$. Then, a sliding motion takes place when the system trajectory reaches the surface $\sigma_{\mathrm{r}}=0$ [37].

Let $t_{\mathrm{sr}}$ be the time required for $\sigma_{\mathrm{r}}$ to reach zero. Assuming that $t_{0}=0$ and $\sigma_{\mathrm{r}}(\mathbf{x}, t)>0$, and by integrating (13) between $t=t_{0}$ and $t=t_{\mathrm{sr}}$, it is found that $\sigma_{\mathrm{r}}(\mathbf{x}, t)=0$ if $t_{\mathrm{sr}}=\frac{\sigma_{\mathrm{r}}\left(\mathbf{x}, t_{0}\right)}{\eta}$. Similarly, it is found that if $\sigma_{\mathrm{r}}\left(\mathbf{x}, t_{0}\right)<0$ then $\sigma_{\mathrm{r}}(\mathbf{x}, t)=0$ with $t_{\mathrm{sr}}=-\frac{\sigma_{\mathrm{r}}\left(\mathbf{x}, t_{0}\right)}{\eta}$. Combining both cases, $t_{\mathrm{sr}}=\frac{\left|\sigma_{\mathrm{r}}\left(\mathbf{x}, t_{0}\right)\right|}{\eta}$ is obtained. The larger $\eta$ is, the faster $\sigma_{\mathrm{r}}$ approaches zero. However, such a strategy implies higher control efforts.

Consider that $x_{7} \geqslant 0$. When $\sigma_{\mathrm{b}} \neq 0$ and $\sigma_{\mathrm{r}} \neq 0$, the closed-loop system dynamics are described unambiguously by:

$$
\dot{\mathbf{x}}= \begin{cases}\mathbf{f}_{\mathrm{r}}^{+}(\mathbf{x}) & \text { if } \mathbf{x} \in \mathscr{X}_{\mathrm{r}}^{+} \\ \mathbf{f}_{\mathrm{r}}^{-}(\mathbf{x}) & \text { if } \mathbf{x} \in \mathscr{X}_{\mathrm{r}}^{-}\end{cases}
$$

with $\mathscr{X}_{\mathrm{r}}^{+}:=\left\{\mathbf{x} \in \mathbb{R}^{9}: \sigma_{\mathrm{r}}(\mathbf{x}, t)>0, \sigma_{\mathrm{b}}(\mathbf{x})>0\right\}, \mathscr{X}_{\mathrm{r}}^{-}:=\left\{\mathbf{x} \in \mathbb{R}^{9}: \sigma_{\mathrm{r}}(\mathbf{x}, t)<0, \sigma_{\mathrm{b}}(\mathbf{x})>0\right\}$. There is no standard equilibrium point in $\mathscr{X}_{\mathrm{r}}^{+}$and in $\mathscr{X}_{\mathrm{r}}^{-}$, that is, $\nexists \overline{\mathbf{x}}$ such that $\mathbf{f}_{\mathrm{r}}^{+}(\overline{\mathbf{x}})=0$ or $\mathbf{f}_{\mathrm{r}}^{-}(\overline{\mathbf{x}})=0$. Therefore, the equilibria are located on the different switching surfaces. As a matter of fact, there are four switching surfaces in the closed-loop system: 


$$
\begin{aligned}
& \Sigma_{\mathrm{r}}^{+}:=\left\{\mathbf{x} \in \mathbb{R}^{9}, t \geqslant t_{\mathrm{sr}}: \sigma_{\mathrm{r}}(\mathbf{x}, t)=0, \sigma_{\mathrm{b}}(\mathbf{x})>0\right\}, \\
& \Sigma_{\mathrm{rb}}:=\left\{\mathbf{x} \in \mathbb{R}^{9}, t \geqslant t_{\mathrm{sr}}: \sigma_{\mathrm{r}}(\mathbf{x}, t)=0, \sigma_{\mathrm{b}}(\mathbf{x})=0\right\}, \\
& \Sigma_{\mathrm{b}}^{+}:=\left\{\mathbf{x} \in \mathbb{R}^{9}, t<t_{\mathrm{sr}}: \sigma_{\mathrm{r}}(\mathbf{x}, t)>0, \sigma_{\mathrm{b}}(\mathbf{x})=0\right\}, \\
& \Sigma_{\mathrm{b}}^{-}:=\left\{\mathbf{x} \in \mathbb{R}^{9}, t<t_{\mathrm{sr}}: \sigma_{\mathrm{r}}(\mathbf{x}, t)<0, \sigma_{\mathrm{b}}(\mathbf{x})=0\right\} .
\end{aligned}
$$

The system trajectories in $\Sigma_{\mathrm{r}}^{+}$are governed by $\dot{\mathbf{x}}=f_{\mathrm{sr}}(\mathbf{x})$, where $f_{\mathrm{sr}}$ is the equivalent dynamics in $\Sigma_{\mathrm{r}}^{+}$[31,37]. The dynamical behaviour in $\Sigma_{\mathrm{r}}^{+}$is determined by the stability properties of the quasiequilibrium point of $\dot{\mathbf{x}}=f_{\mathrm{sr}}(\mathbf{x})$, which is denoted by $\tilde{\mathbf{x}}_{\mathrm{r}}^{+}$ and has the form

$$
\begin{aligned}
& \tilde{x}_{\mathrm{r}, 1}^{+}=\tilde{x}_{\mathrm{r}, 3}^{+}=\tilde{x}_{\mathrm{r}, 5}^{+}=\tilde{x}_{\mathrm{r}, 7}^{+}=\Omega, \\
& \tilde{x}_{\mathrm{r}, 2}^{+}=\frac{h(\Omega)}{k_{\mathrm{t}}}, \quad \tilde{x}_{\mathrm{r}, 4}^{+}=\frac{h(\Omega)}{k_{\mathrm{tl}}}, \quad \tilde{x}_{\mathrm{r}, 6}^{+}=\frac{h(\Omega)}{k_{\mathrm{tb}}}, \quad h(\Omega)=c_{\mathrm{b}} \Omega+T_{\mathrm{f}_{\mathrm{b}}}^{+}(\Omega) .
\end{aligned}
$$

There are no quasiequilibrium points in $\Sigma_{\mathrm{rb}}, \Sigma_{\mathrm{b}}^{+}$, and $\Sigma_{\mathrm{b}}^{-}$, consequently, the permanent stuck-bit situation is eliminated. To conclude with, $\tilde{\mathbf{x}}_{\mathrm{r}}^{+}$is the unique equilibrium point in the closed-loop system. Furthermore, it is asymptotically stable depending on $\Omega, W_{\mathrm{ob}}$ and $\lambda_{\mathrm{r}}$. This is treated in Section 4.2.

\subsection{Quasiequilibrium stability and stick-slip motion}

From Proposition 2, the closed-loop system trajectories evolve towards $\sigma_{\mathrm{r}}=0$, and enter either $\Sigma_{\mathrm{r}}^{+}$or $\Sigma_{\mathrm{rb}}$. When $t \geqslant t_{\mathrm{sr}}$, there are two scenarios: (1) if $\tilde{\mathbf{x}}_{\mathrm{r}}^{+}$is asymptotically stable, the trajectory will stay on $\Sigma_{\mathrm{r}}^{+}$and converge to $\tilde{\mathbf{x}}_{\mathrm{r}}^{+}$, achieving the control goal; (2) if $\tilde{\mathbf{x}}_{\mathrm{r}}^{+}$is unstable, the system trajectory may leave $\Sigma_{\mathrm{r}}^{+}$, and thereafter will alternate sliding motions between $\Sigma_{\mathrm{rb}}$ and $\Sigma_{\mathrm{r}}^{+}$. This behaviour is due to the fact that $\Sigma_{\mathrm{rb}}$ becomes attractive in spite of not containing a quasiequilibrium. Thus, the stick-slip motion arises.

Next, it is shown that $\tilde{\mathbf{x}}_{\mathrm{r}}^{+}$is unstable for reference velocities $\Omega \leqslant \Omega^{*}$, and an estimation of $\Omega^{*}$ is obtained. The stability analysis of the 4-DOF system is equivalent to that of the 2-DOF system. Hence, the stability of the quasiequilibrium point in $\Sigma_{\mathrm{r}}^{+}$ will be analysed from the following 2-DOF system extracted from [19,26]:

$$
\begin{aligned}
& \dot{x}_{1}=\frac{1}{J_{\mathrm{r}}}\left[-\left(c_{\mathrm{t}}+c_{\mathrm{r}}\right) x_{1}-k_{\mathrm{t}} x_{2}+c_{\mathrm{t}} x_{3}+u\right], \\
& \dot{x}_{2}=x_{1}-x_{3}, \\
& \dot{x}_{3}=\frac{1}{J_{\mathrm{b}}}\left[c_{\mathrm{t}} x_{1}+k_{\mathrm{t}} x_{2}-\left(c_{\mathrm{t}}+c_{\mathrm{b}}\right) x_{3}-T_{f_{\mathrm{b}}}\left(x_{3}\right)\right],
\end{aligned}
$$

with $x_{1}=\dot{\varphi}_{\mathrm{r}}, x_{2}=\varphi_{\mathrm{r}}-\varphi_{\mathrm{b}}, x_{3}=\dot{\varphi}_{\mathrm{b}}$. The following control is applied to (18)

$$
u=c_{\mathrm{t}}\left(x_{1}-x_{3}\right)+k_{\mathrm{t}} x_{2}+c_{\mathrm{r}} x_{1}-J_{\mathrm{r}}\left[\lambda_{\mathrm{r}}\left(x_{1}-\Omega\right)+\lambda_{\mathrm{r}}\left(x_{1}-x_{3}\right)+\eta \operatorname{sign}\left(\sigma_{\mathrm{r}}\right)\right],
$$

where $\sigma_{\mathrm{r}}=\left(x_{1}-\Omega\right)+\lambda_{\mathrm{r}} \int_{0}^{t}\left[x_{1}(\tau)-\Omega\right] \mathrm{d} \tau+\lambda_{\mathrm{r}} \int_{0}^{t}\left[x_{1}(\tau)-x_{3}(\tau)\right] \mathrm{d} \tau$. The characteristic polynomial of the Jacobian matrix of the equivalent dynamics in $\Sigma_{\mathrm{r}}^{+}$, evaluated at $\tilde{\mathbf{x}}_{\mathrm{r}}^{+}$is

$$
\begin{aligned}
& \lambda^{3}+a_{2} \lambda^{2}+a_{1} \lambda+a_{0}=0, \\
& a_{0}=\frac{k_{\mathrm{t}} \lambda_{\mathrm{r}}}{J_{\mathrm{b}}}, \quad a_{1}=\frac{1}{J_{\mathrm{b}}}\left[k_{\mathrm{t}}+\lambda_{\mathrm{r}}\left(2 c_{\mathrm{b}}+c_{\mathrm{t}}+2 d_{\mathrm{b}}\right)\right], \quad a_{2}=\frac{1}{J_{\mathrm{b}}}\left(c_{\mathrm{b}}+c_{\mathrm{t}}+d_{\mathrm{b}}+2 \lambda_{\mathrm{r}} J_{\mathrm{b}}\right)
\end{aligned}
$$

with $d_{\mathrm{b}}=-W_{\mathrm{ob}} R_{\mathrm{b}} \frac{\gamma_{\mathrm{b}}}{v_{\mathrm{f}}}\left(\mu_{\mathrm{s}_{\mathrm{b}}}-\mu_{\mathrm{c}_{\mathrm{b}}}\right) \mathrm{e}^{-\frac{\gamma_{\mathrm{b}}}{v_{\mathrm{f}}}}$. The local asymptotic stability of $\tilde{\mathbf{x}}_{\mathrm{r}}^{+}$can be assured by means of the Routh-Hurwitz criterion, that is, when

$$
a_{0}>0, \quad a_{1}>0, \quad \Delta_{2}=a_{1} a_{2}-a_{0}>0 .
$$

In general, safe ranges of $W_{\mathrm{ob}}$ and $\Omega$ can be calculated for fixed values of $\lambda_{\mathrm{r}}$. As an example, using the data of (6), the plots of $a_{1}$ and $\Delta_{2}$ as functions of $W_{\mathrm{ob}}$ and $\Omega$ are shown in Fig. 4. From these plots, it is clear that there exists a $\Omega^{*}$ for which $\tilde{\mathbf{x}}_{\mathrm{r}}^{+}$is asymptotically stable provided that $\Omega>\Omega^{*}$.

For typical values of $W_{\mathrm{ob}}$, and parameters (6), $\Omega^{*}$ is next to $4 \mathrm{rad} / \mathrm{s}$. Stick-slip self-excited oscillations are present when $\Omega \leqslant \Omega^{*}$. Fig. 5 shows the case of $\Omega=2 \mathrm{rad} / \mathrm{s}$. Taking into account that typical drillstring rotary velocities are $9 \mathrm{rad} / \mathrm{s} \leqslant \Omega \leqslant 14 \mathrm{rad} / \mathrm{s}$, the controller proposed is valid.

\section{Simulation results and implementation issues}

\subsection{Performance of the controlled system}

In this section, the performance of the control applied to system (5) with parameters (6) is studied through a series of simulations. A typical drilling operation velocity of $\Omega=12 \mathrm{rad} / \mathrm{s}$ is used. Although, it was found that results with other velocity values are similar provided that $\Omega>\Omega^{*}$. 


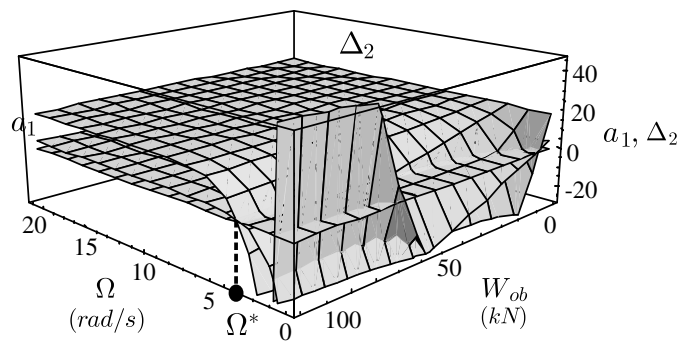

Fig. 4. Evaluation of the Routh-Hurwitz stability conditions for $\tilde{\mathbf{x}}_{\mathrm{r}}^{+}$for the controlled system with $n=3$, for varying $W_{\mathrm{ob}}$ and $\Omega$ and a fixed value $\lambda_{\mathrm{r}}=0.3$.

(1)

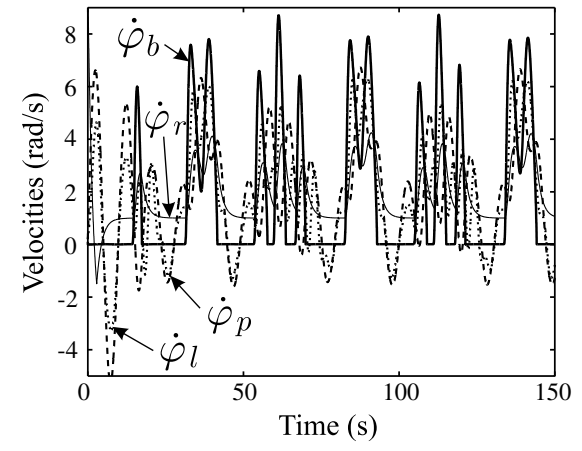

(2)

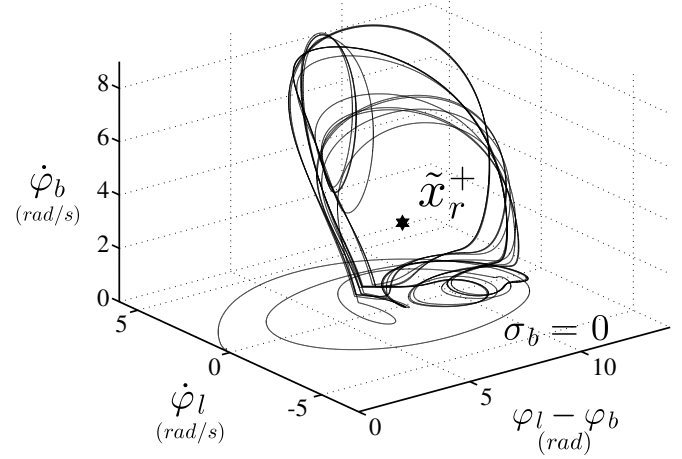

Fig. 5. Stick-slip in the closed-loop system when $\tilde{\mathbf{x}}_{\mathrm{r}}^{+}$is unstable for $\Omega=2 \mathrm{rad} / \mathrm{s}, W_{\mathrm{ob}}=97347 \mathrm{~N}$ : (1) angular velocities, (2) trajectory of the system in the space $\left(\varphi_{1}-\varphi_{\mathrm{b}}, \dot{\varphi}_{\mathrm{l}}, \dot{\varphi}_{\mathrm{b}}\right)$.

In order to avoid chattering along $\sigma_{\mathrm{r}}=0$, the sign function is replaced by a saturation function. For instance [31,39]:

$$
\operatorname{sat}\left(\sigma_{\mathrm{r}} / \delta\right)= \begin{cases}-1 & \text { if } \sigma_{\mathrm{r}}(\mathbf{x}, t)<\delta \\ \frac{\sigma_{\mathrm{r}}}{\delta} & \text { if }\left|\sigma_{\mathrm{r}}(\mathbf{x}, t)\right| \leqslant \delta \\ 1 & \text { if } \sigma_{\mathrm{r}}(\mathbf{x}, t)>\delta\end{cases}
$$

with $\delta>0$ the boundary layer of $\sigma_{\mathrm{r}}$. Using (21), relation (13) takes the form:

$$
\dot{\sigma}_{\mathrm{r}}=-\eta \operatorname{sat}\left(\sigma_{\mathrm{r}} / \delta\right) \text {, }
$$

and controller (14) is rewritten as

$$
u=c_{\mathrm{t}}\left(x_{1}-x_{3}\right)+k_{\mathrm{t}} x_{2}+c_{\mathrm{r}} x_{1}-J_{\mathrm{r}}\left[\lambda_{\mathrm{r}}\left(x_{1}-\Omega\right)+\lambda_{\mathrm{r}}\left(x_{1}-x_{7}\right)+\eta \operatorname{sat}\left(\sigma_{\mathrm{r}} / \delta\right)\right] .
$$

From Eq. (22) it is found that the time required for $\sigma_{\mathrm{r}}$ to reach the boundary layer is $t_{\delta}=\left|\sigma_{\mathrm{r}}\left(\mathbf{x}, t_{0}\right)-\delta\right| / \eta$. Using the saturation function, the equivalent dynamics in $\Sigma_{\mathrm{r}}^{+}$and $\Sigma_{\mathrm{rb}}$ do not change.

Fig. 6(1) shows the elimination of stick-slip oscillations depicted in Fig. 3 when control (23) with (12) is applied to system (5). Here, $W_{\mathrm{ob}}=97347 \mathrm{~N}, \eta=3, \lambda_{\mathrm{r}}=0.3, \delta=0.001$. The control goal is met in reasonable time.

\subsection{Some robustness features}

To show some of the robustness properties of the controlled system under some parameters variation, instead of control (23), the following control is used

$$
u=\Delta_{1} c_{\mathrm{t}}\left(x_{1}-x_{3}\right)+\Delta_{2} k_{\mathrm{t}} x_{2}+\Delta_{3} c_{\mathrm{r}} x_{1}-J_{\mathrm{r}}\left[\lambda_{\mathrm{r}}\left(x_{1}-\Omega\right)+\lambda_{\mathrm{r}}\left(x_{1}-x_{7}\right)+\eta \operatorname{sat}\left(\sigma_{\mathrm{r}} / \delta\right)\right],
$$

with $\Delta_{i}$ being positive constants. According to typical system parameters values, with $0<\Delta_{i} \leqslant 1$ a reasonable variation range of control parameters is covered.

It can be proved that with controller (24), the sliding motion in $\Sigma_{\mathrm{r}}^{+}$is preserved if

$$
|\phi(\mathbf{x})|<\eta,
$$

with $\phi(\mathbf{x})=\left(\Delta_{1}-1\right) \frac{c_{\mathrm{t}}}{J_{\mathrm{r}}}\left(x_{1}-x_{3}\right)+\left(\Delta_{2}-1\right) \frac{k_{\mathrm{t}}}{J_{\mathrm{r}}} x_{2}+\left(\Delta_{3}-1\right) \frac{c_{\mathrm{r}}}{J_{\mathrm{r}}} x_{1}$. Results with $\Delta_{1}=0.7, \Delta_{2}=\Delta_{3}=0.8$ are shown in Fig. 6(2). 
(1)

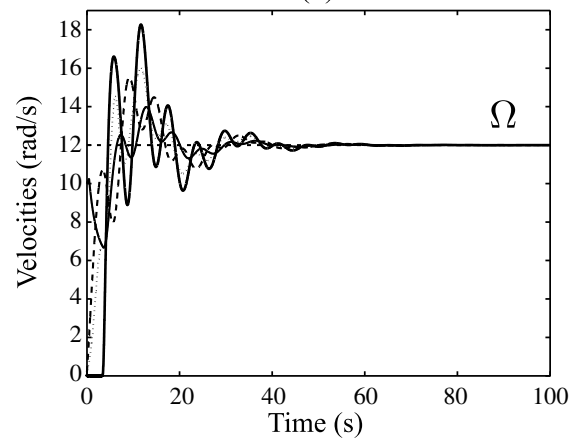

(2)

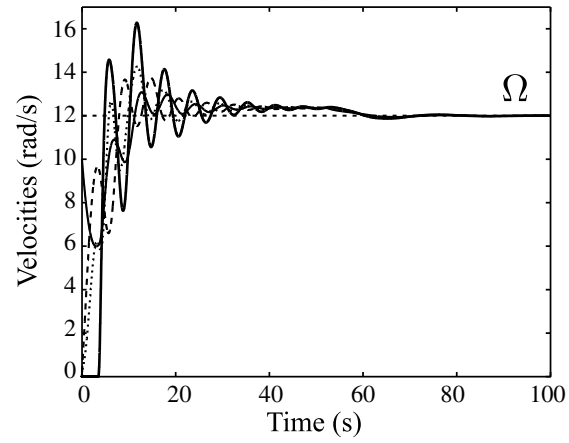

Fig. 6. Angular velocities for the closed-loop system with and without disturbance of controller terms: (1) controller (23)-(12) is used, (2) controller (24)(12) is used.

The control goal is achieved despite $W_{\mathrm{ob}}$ variations and without depending on the bit situation. This fact and the robustness under system parameters variations are remarkable properties of the controller proposed.

From Fig. 6, it can be also observed that the proposed sliding-mode control has the advantage that with relatively low gains $\left(\lambda_{\mathrm{r}}, \eta\right)$, the control goal is achieved with good system performance. The settling time is approximately $50 \mathrm{~s}$, which is acceptable considering typical drillstring dynamics and that it is better avoiding failures than having smaller settling-time values. Furthermore, during the settling-time, the system does not enter the sticking region for a long time; this is not easily obtained with other classical controllers. For instance, consider a PI-type controller [33]:

$$
u=K_{1} \int_{0}^{t}\left[\Omega-x_{1}(\tau)\right] \mathrm{d} \tau+K_{2}\left(\Omega-x_{1}\right)+K_{3} P(\mathbf{x}),
$$

with $P(\mathbf{x})=\int_{0}^{t}\left[x_{1}(\tau)-x_{7}(\tau)\right] \mathrm{d} \tau$ or $P(\mathbf{x})=x_{1}-x_{7}$. Fig. $7(1)$ shows the velocities of the system controlled by (26) with $K_{1}=30, K_{2}=10, K_{3}=20$, and $W_{\mathrm{ob}}=97347 \mathrm{~N}$. The comparison of the performance of controllers (23) and (26) is shown in Fig. 7(2). Three disadvantages of the PI-type control can be observed from this figure. First, the controller gains $\left(K_{i}\right)$ must be high enough for avoiding permanent sticking situations. Second, during the settling time, the bit enters the sticking region for a long time. Third, drillstring components velocities can be negative, which can generate important fatigue and other problems.

Furthermore, for the sliding-based-controlled system with $\Omega>\Omega^{*}$, there is no periodic orbit. This is not the case for the PI-type-controlled system. For example, for control (26) with $P(\mathbf{x})=x_{1}-x_{7}$, sets of periodic orbits may arise from different Hopf bifurcations depending basically on $\Omega, W_{\text {ob }}$ and $K_{3}$. This is shown in Fig. 8.

Finally, it must be pointed out that the introduction of an automated controlled drilling system can be unfeasible due to the complexity of oilwell drillstrings and drilling practices. The proposed controller should be understood as an off-line safeparameters selection method in order to guide the driller to avoid bit sticking problems and to reach the control goal. The model and controller proposed can help the driller to design the well drilling profile with reference values for $u, W_{\mathrm{ob}}$ and $\Omega$ before starting the operation. For a combination of $\left(W_{\mathrm{ob}}, \Omega\right)$, the torque $u$ could be calculated to prevent non-desired bit phenomena.

(1)

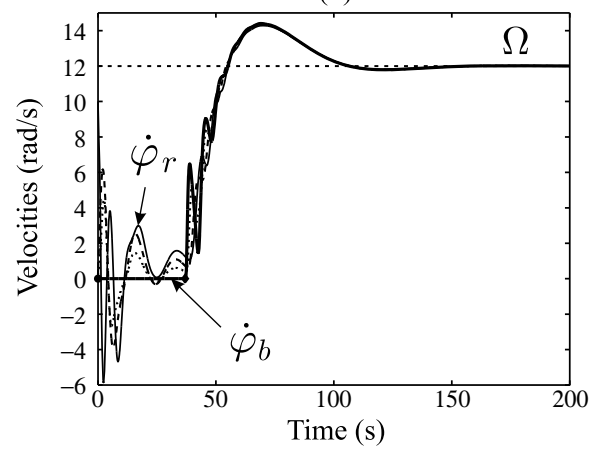

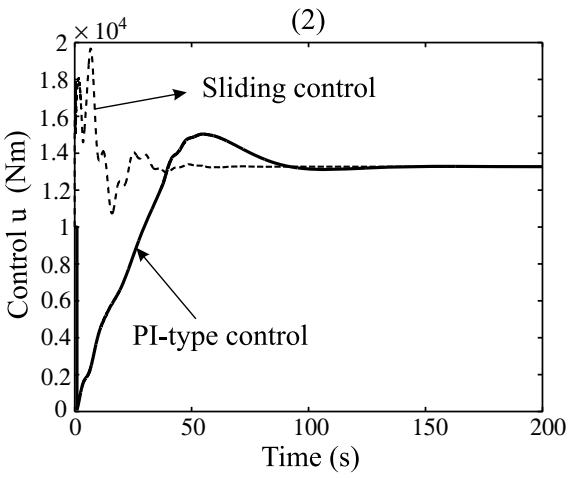

Fig. 7. System (5) response with a PI-type controller (26): (1) angular velocities, (2) PI control compared to the sliding-mode control (23) with $\lambda_{\mathrm{r}}=0.3, \eta=3$. 
(1)

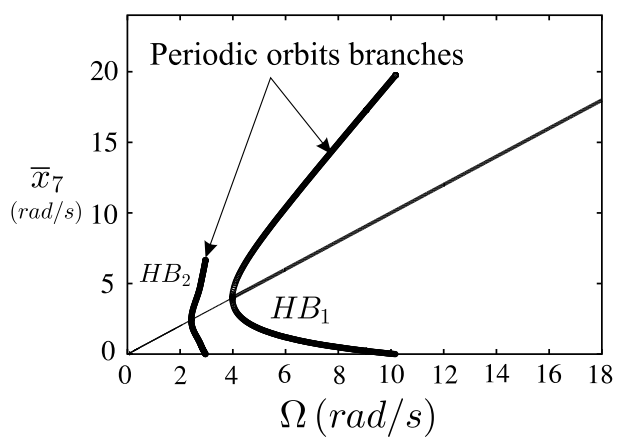

(3)

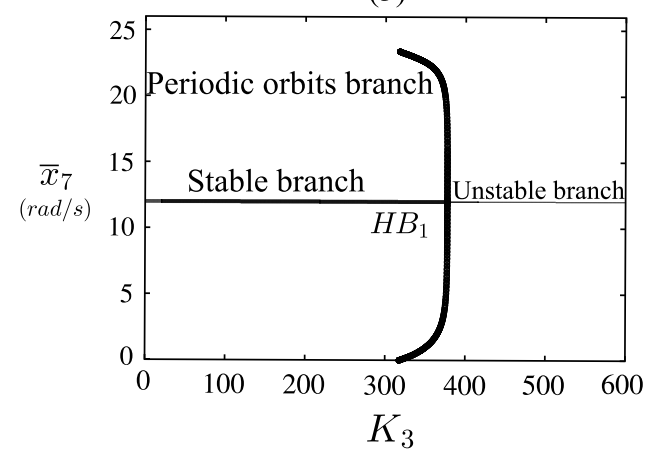

(2)

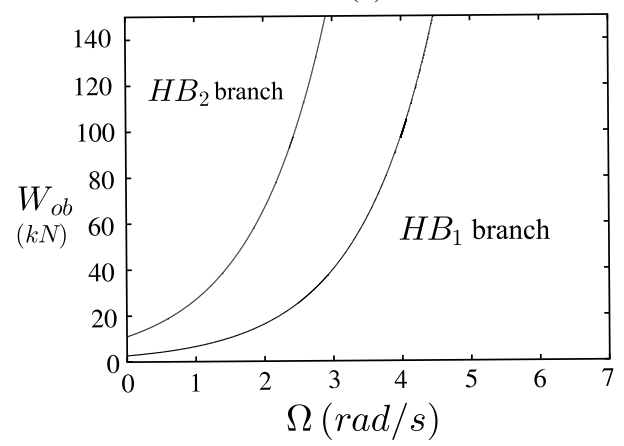

(4)

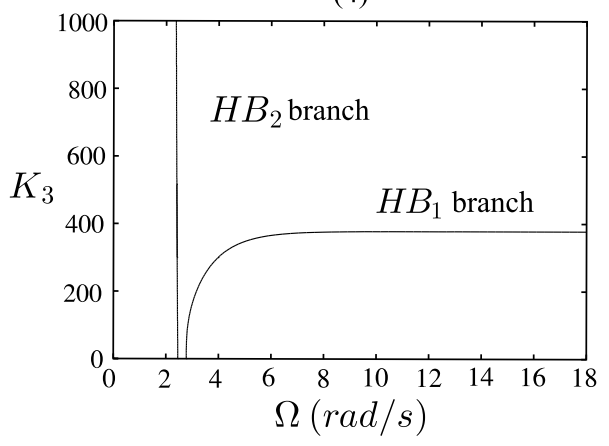

Fig. 8. Bifurcation diagrams for system (5) with the PI-type controller (26) and $P(\mathbf{x})=x_{1}-x_{7}$. Fixed $K_{1}=30, K_{2}=10$ are used. The bifurcation diagrams have been obtained with XPPAUT [38].

\section{Conclusions}

A novel method for the characterisation and control of drillstring stick-slip oscillations is proposed. A four-degree-of-freedom model under the influence of the weight on the bit, the top-rotary-system torque and the rotary drilling velocity is considered. A dynamical sliding-mode control is used to eliminate bit sticking phenomena. In the closed-loop system, the angular velocities are driven to a desired reference value in spite of weight-on-bit variations and the presence of a dry friction modelling the bit-rock contact. The key idea of the controller is to introduce in the system a sliding surface in which the desired dynamics are accomplished. Robustness under parameters variations is also shown. A crucial feature of the closedloop system is the existence of multiple switching surfaces. The analysis of such a system is possible by studying the properties of the unique quasiequilibrium of the closed-loop system. Although the stick-slip motion is present in the controlled system, the velocities values for which this phenomenon is avoided are identified.

\section{Acknowledgements}

The first author is indebted to Dr. Domingo Cortés Rodríguez for his guidance in sliding-mode analysis and for his creative and practical viewpoint of control. Part of this work was developed under the support of Ministerio de Ciencia e Innovación of Spain (former Ministerio de Educación y Ciencia) under a Ramón y Cajal research contract.

\section{References}

[1] Dankowicz H, Nordmark AB. On the origin and bifurcations of stick-slip oscillations. Physica D 2000;136:280-302.

[2] Franca LFP, Weber HI. Experimental and numerical study of a new resonance hammer drilling model with drift. Chaos, Solitons \& Fractals 2004:21:789-801.

[3] Galvanetto U. Some discontinuous bifurcations in a two-block stick-slip system. J Sound Vib 2001;248(4):653-69.

[4] Galvanetto U. Characterisation of the dynamics of a four-dimensional stick-slip system by a scalar variable. Chaos, Solitons \& Fractals 1995;5(11):2171-9.

[5] Hinrichs N, Oestreich M, Popp K. Dynamics of oscillators with impact and friction. Chaos, Solitons \& Fractals 1997;8(4):535-58.

[6] Leine RI, van Campen DH, van de Vrande BL. Bifurcations in nonlinear discontinuous systems. Nonlinear Dynam 2000;23(2):105-64.

[7] Stelter P, Sextro W. Bifurcations in dynamic systems with dry friction. Int Series Numerical Math 1991;97:343-7.

[8] Yang FH, Zhang W, Wang J. Sliding bifurcations and chaos induced by dry friction in a braking system. Chaos, Solitons \& Fractals 2009;40:1060-75.

[9] Blazejczyk-Okolewska B, Kapitaniak T. Dynamics of impact oscillator with dry friction. Chaos, Solitons \& Fractals 1996;7(9):1455-9.

[10] Dankowicz H, Piiroinen P, Nordmark AB. Low-velocity impacts of quasiperiodic oscillations. Chaos, Solitons \& Fractals 2002;14:241-55. 
[11] Czolczyński K, Kapitaniak T. Influence of the mass and stiffness ratio on a periodic motion of two impacting oscillators. Chaos, Solitons \& Fractals 2003;17:1-10.

[12] Karpenko EV, Wiercigroch M, Cartmell MP. Regular and chaotic dynamics of a discontinuously nonlinear rotor system. Chaos, Solitons \& Fractals 2002;13:1231-42.

[13] Luo ACJ, Chen L. Periodic motions and grazing in a harmonically forced, piecewise, linear oscillator with impacts. Chaos, Solitons \& Fractals 2005;24:567-78.

[14] Luo G, Xie J, Zhu X, Zhang J. Periodic motions and bifurcations of a vibro-impact system. Chaos, Solitons \& Fractals 2008;36:1340-7.

[15] Wagg DJ. Rising phenomena and the multi-sliding bifurcation in a two-degree of freedom impact oscillator. Chaos, Solitons \& Fractals 2004;22:541-8.

[16] Wojewoda J, Kapitaniak T, Barron R, Brindley J. Complex behaviour of a quasiperiodically forced experimental system with dry friction. Chaos, Solitons \& Fractals 1993;3(1):35-46.

[17] Dabrowski A, Kapitaniak T. Using chaos to reduce oscillations: experimental results. Chaos, Solitons \& Fractals 2009;39:1677-83.

[18] Wiercigroch M, Wojewoda J, Krivtsov AM. Dynamics of ultrasonic percussive drilling of hard rocks. J Sound Vib 2005;280:739-57.

[19] Navarro-López EM, Cortés D. Avoiding harmful oscillations in a drillstring through dynamical analysis. J Sound Vib 2007;307(1-2):152-71.

[20] Abbassian F, Dunayevsky VA. Application of stability approach to torsional and lateral bit dynamics. SPE Drill Complet 1998;13(2):99-107.

[21] Brett JF. The genesis of torsional drillstring vibrations. SPE Drilling Eng 1992(September):168-74.

[22] Jansen JD, van den Steen L. Active damping of self-excited torsional vibrations in oil well drillstrings. J Sound Vib 1995;179(4):647-68.

[23] Halsey GW, Kyllingstad Å, Kylling A. Torque feedback used to cure slip-stick motion. In: 63rd SPE annual technical conference and exhibition; 1988. p. 277-82.

[24] Lin YQ, Wang YH. Stick-slip vibration of drill strings. J Eng Ind 1991;113:38-43.

[25] Navarro-López EM, Suárez-Cortez R. Practical approach to modelling and controlling stick-slip oscillations in oilwell drillstrings. In: IEEE international conference on control applications, Taipei, Taiwan; 2004. p. 1454-60.

[26] Navarro-López EM, Suárez-Cortez R. Vibraciones mecánicas en una sarta de perforación: problemas de control. Rev Iberoamericana Aut Inform Ind $2005 ; 2(1): 43-54$.

[27] Serrarens AFA, van de Molengraft MJG, Kok JJ, van den Steen L. $H_{\infty}$ control for suppressing stick-slip in oil well drillstrings. IEEE Control Syst 1998;April:19-30.

[28] Yigit AS, Christoforou AP. Coupled torsional and bending vibrations of actively controlled drillstrings. J Sound Vib 2000;234(1):67-83.

[29] van der Heijden GHM. Bifurcation and chaos in drillstring dynamics. Chaos, Solitons \& Fractals 1993;3(2):219-47.

[30] Leine RI, van Campen DH, Keultjes WJG. Stick-slip whirl interaction in drillstring dynamics. J Vib Acoust 2002;124:209-20.

[31] Utkin VI, Guldner J, Shi J. Sliding mode control in electromechanical systems. Taylor Francis 1999.

[32] Pavone DR and Desplans JP. Application of high sampling rate downhole measurements for analysis and cure of stick-slip in drilling. In: SPE annual technical conference and exhibition, New Orleans, Louisiana; 1994. p. 335-45.

[33] Navarro-López EM, Cortés D. Controller parameters selection through bifurcation analysis in a piecewise-smooth system. Lecture notes in computer science, 4416. Berlin: Springer-Verlag; 2007. p. 736-40.

[34] Navarro-López EM, Cortés D. Sliding-mode control of a multi-DOF oilwell drillstring with stick-slip oscillations. In: American control conference, New York, USA; 2007. p. 3837-42.

[35] Tri-cone bits manual. USA: Hughes Tool Company, 1982.

[36] Kuznetsov YA, Rinaldi S, Gragnani A. One-parameter bifurcations in planar Filippov systems. Int J Bifurcations Chaos 2003;13(8):2157-88.

[37] Filippov AF. Differential equations with discontinuous right-hand sides. Dordrecht: Kluwer Academic Publishers; 1988.

[38] Ermentrout B. Simulating, analyzing, and animating dynamical systems (a guide to XPPAUT for researchers and students). SIAM Software Environ Tools 2002.

[39] van de Vorst ELB, van Campen DH, de Kraker A, Kok JJ, Fey RHB. Vibration control of periodically excited nonlinear dynamic multi-dof systems. J Vib Control 1995;1:575-92. 